\title{
Exploring the norms of eating-out practice among adults in Malaysia
}

\section{Lydiatul Shima Ashari ${ }^{1}$, Ainaa Almardhiyah Abd Rashid ${ }^{1}$, Mohd Razif Shahril ${ }^{2}$, Yeong Yeh Lee ${ }^{3,4}$, Yee Cheng Kueh ${ }^{5}$, Bibi Nabihah Abdul Hakim ${ }^{1}$, Nor Hamizah Shafiee $^{6}$, Raja Affendi Raja Ali ${ }^{7,8}$ \& Hamid Jan Jan Mohamed ${ }^{1^{*}}$}

${ }^{1}$ Nutrition and Dietetics Programme, School of Health Sciences, Universiti Sains Malaysia, Kelantan, Malaysia; ${ }^{2}$ Nutritional Sciences Programme, Centre for Healthy Ageing and Wellness (HCARE), Faculty of Health Sciences, Universiti Kebangsaan Malaysia, Kuala Lumpur, Malaysia; ${ }^{3}$ School of Medical Sciences, Universiti Sains Malaysia, Kelantan, Malaysia; ${ }^{4}$ GI Function \& Motility Unit, Hospital USM, Universiti Sains Malaysia, Kelantan, Malaysia; ${ }^{\mathbf{5}}$ Biostatistics and Research Methodology Unit, School of Medical Sciences, Universiti Sains Malaysia, Kelantan, Malaysia; ${ }^{6}$ Department of Medicine, Faculty of Medicine, Universiti Kebangsaan Malaysia, Kuala Lumpur, Malaysia; ${ }^{7}$ Gastroenterology Unit, Department of Medicine, UKM Medical Centre, Kuala Lumpur, Malaysia; ${ }^{8}$ Gut research group, Faculty of Medicine, Universiti Kebangsaan Malaysia, Kuala Lumpur, Malaysia

\begin{abstract}
Introduction: Eating-out is common in almost all countries, including Malaysia, but this frequent practice may affect human health. In Malaysia, data on eating-out is limited. This study aimed to assess the proportion of eating-out, to assess the association between socio-demographic factors and eating patterns, and to compare energy and nutrient intakes between people eating-out and eating-in. Methods: This cross-sectional study was conducted among 100 adults aged 30 to 70 years old. Three-day food diaries were used to collect data on dietary intake. Eating-out was defined as eating foods prepared outside the home. Respondents who ate outside for at least one meal per day, for two or three days per week were considered as those who frequently practised eating-out. Results: A total of $84 \%$ of respondents who ate out had significantly higher sodium intake than those who ate at home $(2934$ $\mathrm{mg} /$ day vs. $2165 \mathrm{mg} /$ day, $p=0.025$ ). Foods and drinks that were most commonly consumed outside were nasi lemak, roti canai, rice, ayam masak kicap, vegetable soup, tomyam, rice vermicelli soup (mee-hoon soup), hot teh-o, iced tea, and orange juice. Occupation $(p=0.004)$ and location type $(p=0.001)$ were associated with eatingout. Government and semi-government workers (61\%) and urban population (57\%) had higher percentage of eating-out compared to eating at home $(19 \%$ and $12 \%$, respectively). Conclusion: More than two-thirds of our respondents ate out and this habit was related to poor diet quality with excessive intake of sodium. Interventions are needed to improve the diet quality of the overall eating-out behaviour among targeted population.
\end{abstract}

Keywords: eating pattern, eating-out, factors, nutrients, Malaysia

\footnotetext{
*Corresponding author: Prof. Dr. Hamid Jan Jan Mohamed Nutrition and Dietetics Programme, School of Health Sciences, Universiti Sains Malaysia, Kelantan, Malaysia Tel: (6)(09)7677618; Fax: (6)(09)7677515; E-mail: hamidjan@usm.my doi: https://doi.org/10.31246/mjn-2021-0008
} 


\section{INTRODUCTION}

In recent decades, people around the world were found to have significant shifts in their eating patterns or behaviours. The trend of people eatingout has been increasing as compared to eating at home (eating-in) (Seguin et al., 2016). Eating-out frequently may affect human health. For example, meals purchased outside were found to be a risk factor for cardiovascular diseases due to higher intakes of energy and fat, and malnutrition from the low micronutrient contents (Lachat et al., 2012; Goffe et al., 2017; Kim \& Ahn, 2020). Moreover, the nutritional contents in meals from independent takeaway outlets are inconsistent with national dietary recommendations (Goffe et al., 2017). Mills et al. (2020) have discovered that lesser time spent cooking at home was paralleled with diet-related non-communicable diseases including diabetes mellitus and obesity. In addition, a recent study found that late-night supper could increase the risk of gastroesophageal reflux, especially among obese individuals (Deraman et al., 2020).

Many factors can influence eating-out habit. Socio-economic and demographic factors such as high income and smaller urban household size are part of the determinants of eating-out. Independent of these factors, the urban effect was found to affect the consumption of food away from home. Urbanisation has increased the financial accessibility and availability of various food outlets, which exposes consumers to new dietary options (d'Amour et al., 2020). The increasing number of women in the labour force has also changed the role of women in food provision. Women's employment and a decline in the prevalence of cooking at home have driven an increase in eating food away from home (Kim \& Ahn, 2020). Ready- to-eat foods consumed from outlets, namely cafes, food stalls, food courts, restaurants, and convenience stores are common (Goffe et al., 2017). A study in the United Kingdom (UK) showed that adults and children had a takeaway meal at home on a weekly basis, proving that higher takeaway food intake is related to increased exposure to takeaway outlets (Goffe et al., 2017).

As a developing nation, Malaysia is also experiencing a rapid modernisation process with expansive urbanisation programme and rural withdrawal (Fournier et al., 2016), and the growing economy is associated with an increase in income. The increase in income allows more purchase and food consumption including eating-out. The Malaysian Adult Nutrition Survey (MANS, 2014) has highlighted a high frequency of eating outside linked with urbanisation. The growth of urbanisation results in the development of a food environment with a high density of outlets, thus increases the opportunity for Malaysians to eat outside (Poulain et al., 2020). Other factors include working mothers who have no time to cook at home and the expansion of premises serving a variety of foods, both of which have ignited the recent practice of eating-out in Malaysia (Ali \& Abdullah, 2012).

Secondary data from several states in Malaysia including Selangor, Kedah and Johor revealed that the habits of eating-out among students, workers and families were due to the unavailability of foods at home or they could not go home to eat (Ali \& Abdullah, 2012). An earlier study on the eating patterns in Malaysia had discussed the patterns and implications of eating-out (Ali \& Abdullah, 2012), while another study explored the issue of body mass index (BMI) with socio-demographic and the link between eating-out and obesity (Fournier et al., 2016). However, 
many issues remain unclear, and the information is limited, especially on the latest rates, associated factors, energy intakes, and nutrient intakes. Therefore, the current study aimed to assess the proportion of eating-out, to assess the association between socio-demographic factors and eating patterns, and to compare energy and nutrient intakes between people eating-out and eating-in.

\section{MATERIALS AND METHODS}

\section{Definition of eating-out}

There has been various definitions of eating-out applied in various populations (Gorgulho, Fisberg \& Marchioni, 2014; Llanaj et al., 2018; Zang et al., 2018). For the current study, eating-out was defined as eating foods prepared outside of the home, such as in restaurants, food courts, fast food joints, hawker stalls etc., and including takeaway or delivery services (e.g., Food Panda, Grab Food etc.) for home, office or indoor consumption (NCCFN, 2019). In addition, we have a quantitative definition for eating-out of at least one meal over two or three days. Respondents who did not meet the above definitions were considered as eating-in.

\section{Study design}

This cross-sectional study was conducted from December 2019 to March 2020 in two cities of Peninsular Malaysia, which were Kuala Lumpur (KL) and Kota Bharu, and they represented the urban and suburban areas, respectively. KL is in Klang Valley, with a population density of 7802 per square kilometre, while Kota Bharu is located in Kelantan, in the north-east of Peninsular Malaysia, with a population density of 1511 per square kilometre according to the Department of Statistics Malaysia, 2019. The sample size was calculated based on single proportion estimation with an expected proportion of 0.24 (Gorgulho et al., 2014) and a precision of 0.09 . The estimated sample size with $10 \%$ dropout was 96 respondents.

Respondents were recruited using the convenience sampling method. The inclusion criteria included individuals aged 30 years and above who did not practise any diet regime [e.g., intermittent fasting, Atkins diet, lowfermentable oligo-, di-, monosaccharide and polyol (FODMAP) etc.]. The study procedure was reviewed and approved by the Human Research Ethics Committee of Universiti Sains Malaysia (USM/JEPeM/19060354) and Universiti Kebangsaan Malaysia's Research Ethics Committee (UKMREC; FF-2020-005). The respondents were recruited into the study after they have provided informed consent.

\section{Dietary data collection}

Dietary information was assessed using three-day food diaries. The three-day food diary included two weekdays and one weekend day per week. As the quantitative definition of eating-out was those who ate outside for at least one meal per day, for two or three days in a week, the multiple recalls or three repeat recalls covering two weekdays and one weekend was the most suitable option to assess the proportion of eating-out. In addition, multiple recalls provided a better capture of the variation in energy and nutrient intakes, as well as episodically-consumed foods between individuals who were eating-out and eating-in. Nevertheless, it is noteworthy that each food assessment method has its strengths and limitations. The three-day food diary included pictures of household measurements, such as tablespoon, teaspoon, cup, glass etc., to aid in the estimation of portion sizes. Other variables included the time of meals, place of eating, types of food and beverages, and the total price for two weekdays and one weekend. Nutritionist 
Pro $^{\mathrm{TM}}$ Diet Analysis Software version 7.8.0 (Axxya Systems, version 2020, Redmond, USA) was used to analyse the dietary data. Recipes and foods were selected from the reference list of Nutrient Composition of Malaysian Foods in the Nutritionist Pro ${ }^{\mathrm{TM}}$ database. Recipes that were not listed in the reference list were added to the database. Portion sizes were calculated based on standard recipe sizes, for example per serving size and total serving. Weight of foods or ingredients to make the recipes were referred from the Nutrient Composition of Malaysian Foods (Tee et al., 1997), Atlas of Food Exchanges \& Portion Sizes (Suzana et al., 2009), Album Makanan Malaysia (IPH, 2011), and Malaysian Food Composition Database (MyFCD, 2020). The nutrition information of food product was obtained from its packaging or MyFCD and was inserted into the database.

\section{Statistical analysis}

Statistical analysis was carried out using IBM SPSS Statistics, Version 22.0 (Chicago, IL, USA). Categorical data were presented as frequencies and percentages. Continuous data with a normal distribution were presented as mean and standard deviation, while skewed data were presented as median and interquartile range. Results of eating-out and eating-in were grouped or tabled according to gender, age, occupation, monthly household income, and location type. The occupation groups of housewife, pensioner, and the unemployed were regrouped into one group, i.e. housewife and not working group, due to small sample size. Differences between the two groups were analysed using Pearson chi-square or Fisher's exact test. Comparisons of energy and nutrient intakes between eating-out and eating-in were analysed using an independent $t$-test or MannWhitney U test.

\section{RESULTS}

Table 1 shows the socio-demographic characteristics of the study population. A total of 100 respondents (38 men and 62 women) participated in the study. The majority of the respondents were 45-59 years old (66\%), Malays (70\%), married $(85 \%)$, had secondary level education $(51 \%)$, worked in the government and semi-government sectors (54\%), had a household member of between 1-5 $(82 \%)$, and had a monthly household income of not more than RM 3860, equivalent to USD 953 (75\%), which was classified as the bottom $40 \%$ of household income group (EPU, 2015). Half of the respondents lived in urban areas, while the other half in suburban locations.

The overall proportion of eatingout was $84 \%$ (Table 2). Eating-out vs. eating-in was significantly associated with occupation $(p=0.004)$ and location $(p=0.001)$. With regards to occupation, we found a higher proportion of eatingout vs. eating-in in the government and semi-government sectors (61\% vs. 19\%), while a lower proportion was observed in the non-government sectors (18\% vs. $44 \%$ ), as well as the housewife and not working category $(21 \%$ vs. $37 \%)$. Furthermore, a higher proportion of eating-out vs. eating-in was observed in the urban areas (57\% vs. $12 \%$ ), but a lower proportion was observed in the suburban (43\% vs. $88 \%$ ) areas.

Figure 1 shows the percentages of eating-out according to meals. The highest proportion of eating-out was observed during lunch time (57\%), followed by breakfast time (46\%), and the least during dinner time (26\%). There was a significant association between gender and the frequency of eating-out during lunch time $(p=0.026)$. A higher proportion of eating-out during lunch time vs. eating-in was observed in men (71\% vs. $29 \%)$, whilst a lower proportion 
Table 1. Characteristics of respondents $(n=100)^{\dagger}$

\begin{tabular}{|c|c|c|c|}
\hline Characteristics & $\begin{array}{c}\text { Men }(n=38) \\
n(\%)\end{array}$ & $\begin{array}{c}\text { Women }(n=62) \\
n(\%)\end{array}$ & $\begin{array}{c}\text { Overall }(n=100) \\
n(\%)\end{array}$ \\
\hline \multicolumn{4}{|l|}{ Age groups (years) } \\
\hline $30-44$ & $4(11)$ & $15(24)$ & 19 (19) \\
\hline $45-59$ & $27(71)$ & 39 (63) & $66(66)$ \\
\hline$\geq 60$ & 7 (18) & $8(13)$ & $15(15)$ \\
\hline \multicolumn{4}{|l|}{ Race } \\
\hline Malay & $24(63)$ & $46(74)$ & $70(70)$ \\
\hline Chinese & $6(16)$ & $11(18)$ & 17 (17) \\
\hline Indian & $8(21)$ & $5(8)$ & $13(13)$ \\
\hline \multicolumn{4}{|l|}{ Marital status } \\
\hline Single & $1(3)$ & $6(10)$ & $7(7)$ \\
\hline Married & $36(94)$ & 49 (79) & $85(85)$ \\
\hline Widower/Widow & $1(3)$ & $6(10)$ & $7(7)$ \\
\hline Divorced & $0(0)$ & $1(1)$ & $1(1)$ \\
\hline \multicolumn{4}{|l|}{ Educational level } \\
\hline Primary school & $1(3)$ & $9(14)$ & $10(10)$ \\
\hline Secondary school & $22(58)$ & $29(47)$ & $51(51)$ \\
\hline University & $14(36)$ & 24 (39) & $38(38)$ \\
\hline Unschooling & $1(3)$ & $0(0)$ & $1(1)$ \\
\hline \multicolumn{4}{|l|}{ Occupation } \\
\hline $\begin{array}{l}\text { Government and semi- } \\
\text { government }\end{array}$ & $22(58)$ & $32(52)$ & $54(54)$ \\
\hline Private & $3(8)$ & $6(10)$ & $9(9)$ \\
\hline $\begin{array}{l}\text { Self-employed/own } \\
\text { business }\end{array}$ & $6(16)$ & $7(11)$ & $13(13)$ \\
\hline Housewife & $0(0)$ & $10(16)$ & $10(10)$ \\
\hline Unemployed & $2(5)$ & $4(6)$ & $6(6)$ \\
\hline Pensioner & $5(13)$ & $3(5)$ & $8(8)$ \\
\hline \multicolumn{4}{|l|}{ Household number } \\
\hline $1-5$ & $32(84)$ & $49(80)$ & $81(82)$ \\
\hline $6-10$ & 5 (13) & $8(13)$ & 13 (13) \\
\hline$\geq 11$ & $1(3)$ & $4(7)$ & $5(5)$ \\
\hline \multicolumn{4}{|l|}{$\begin{array}{l}\text { Monthly household income } \\
\text { (RM) })^{\ddagger}\end{array}$} \\
\hline$<3860$ & $27(71)$ & $48(77)$ & $75(75)$ \\
\hline $3860-8319$ & $10(26)$ & $11(18)$ & $21(21)$ \\
\hline$\geq 8320$ & $1(3)$ & $3(5)$ & $4(4)$ \\
\hline \multicolumn{4}{|l|}{ Living location } \\
\hline Urban & $25(66)$ & $25(40)$ & $50(50)$ \\
\hline Suburban & $13(34)$ & 37 (60) & $50(50)$ \\
\hline
\end{tabular}

TSample size was not always $n=100$ due to missing values

"Based on the cut-offs of the Eleventh Malaysia Plan (2015)

of eating-out during lunch time vs. eating-in was observed in women $(48 \%$ vs. $52 \%)$.

Table 3 shows the energy and nutrient intakes of eating-out and eating-in. Overall, the level of sodium was significantly higher in participants who were eating-out compared to eatingin (2934 vs. 2165, $p=0.025)$. However, there were no significant differences in 
Table 2. Percentage of eating-out and eating-in among respondents: by gender, age groups, occupation, monthly household income, and location type $(n=100)$

\begin{tabular}{|c|c|c|c|}
\hline Variables & $\begin{array}{c}\text { Out of home } \\
n(\%)\end{array}$ & $\begin{array}{l}\text { At home } \\
n(\%)\end{array}$ & $p$-value \\
\hline Gender & & & 0.083 \\
\hline Men & 35 (42) & $3(19)$ & \\
\hline Women & $49(58)$ & $13(81)$ & \\
\hline Age groups (years) & & & 0.275 \\
\hline $30-44$ & $14(17)$ & $5(31)$ & \\
\hline $45-59$ & 58 (69) & $8(50)$ & \\
\hline$\geq 60$ & $12(14)$ & $3(19)$ & \\
\hline Occupation ${ }^{\ddagger}$ & & & $0.004 *$ \\
\hline $\begin{array}{l}\text { Government and semi- } \\
\text { government }\end{array}$ & $51(61)$ & $3(19)$ & \\
\hline Non-government & $15(18)$ & $7(44)$ & \\
\hline $\begin{array}{l}\text { Housewife and not } \\
\text { working }\end{array}$ & $18(21)$ & $6(37)$ & \\
\hline $\begin{array}{l}\text { Monthly household income } \\
\text { (RM) })^{\ddagger}, 9\end{array}$ & & & 0.481 \\
\hline$<3860$ & $62(74)$ & $13(81)$ & \\
\hline $3860-8319$ & 19 (23) & $2(13)$ & \\
\hline$\geq 8320$ & $3(3)$ & $1(6)$ & \\
\hline Location type & & & $0.001^{*}$ \\
\hline Urban & $48(57)$ & $2(12)$ & \\
\hline Suburban & $36(43)$ & $14(88)$ & \\
\hline Overall percentage & 84 & 16 & \\
\hline
\end{tabular}

${ }^{\dagger}$ Chi-square test

${ }^{\ddagger}$ Fisher's exact test

"Based on the cut-offs of the Eleventh Malaysia Plan (2015)

${ }^{*} p<0.05$

total energy, protein, carbohydrate, fat, dietary fibre, and sugar between those eating-out and eating-in.

The list of preferred foods and drinks that study participants consumed outside during breakfast were nasi lemak, roti canai, and hot teh-o. During lunch time, people liked to eat rice, ayam masak kicap, vegetable soup, and iced tea; during dinner, the preferred foods were rice, tomyam, rice vermicelli soup (mee-hoon soup), and orange juice. Most people liked to eat curry puff, jemput pisang, and popcorn chicken (ayam gunting) as snacks.

The list of commonly consumed foods and drinks at home during breakfast were fried noodles (mee goreng), white bread, butter, biscuits, hot teh-o, oat, and low-fat milk powder. During lunch, people mostly consumed rice, ayam masak kicap, and fried vegetables (sayur goreng). For dinner, study participants tended to eat fried noodles.

\section{DISCUSSION}

We found that more than two-thirds $(84 \%)$ of our respondents ate out, mostly during lunch and breakfast. More people are eating-out as a result of the growing number of hawkers, who typically open from 10 a.m. to midnight and offer a wide range of dishes. This pattern was consistent with a previous study conducted in Shanghai, China 


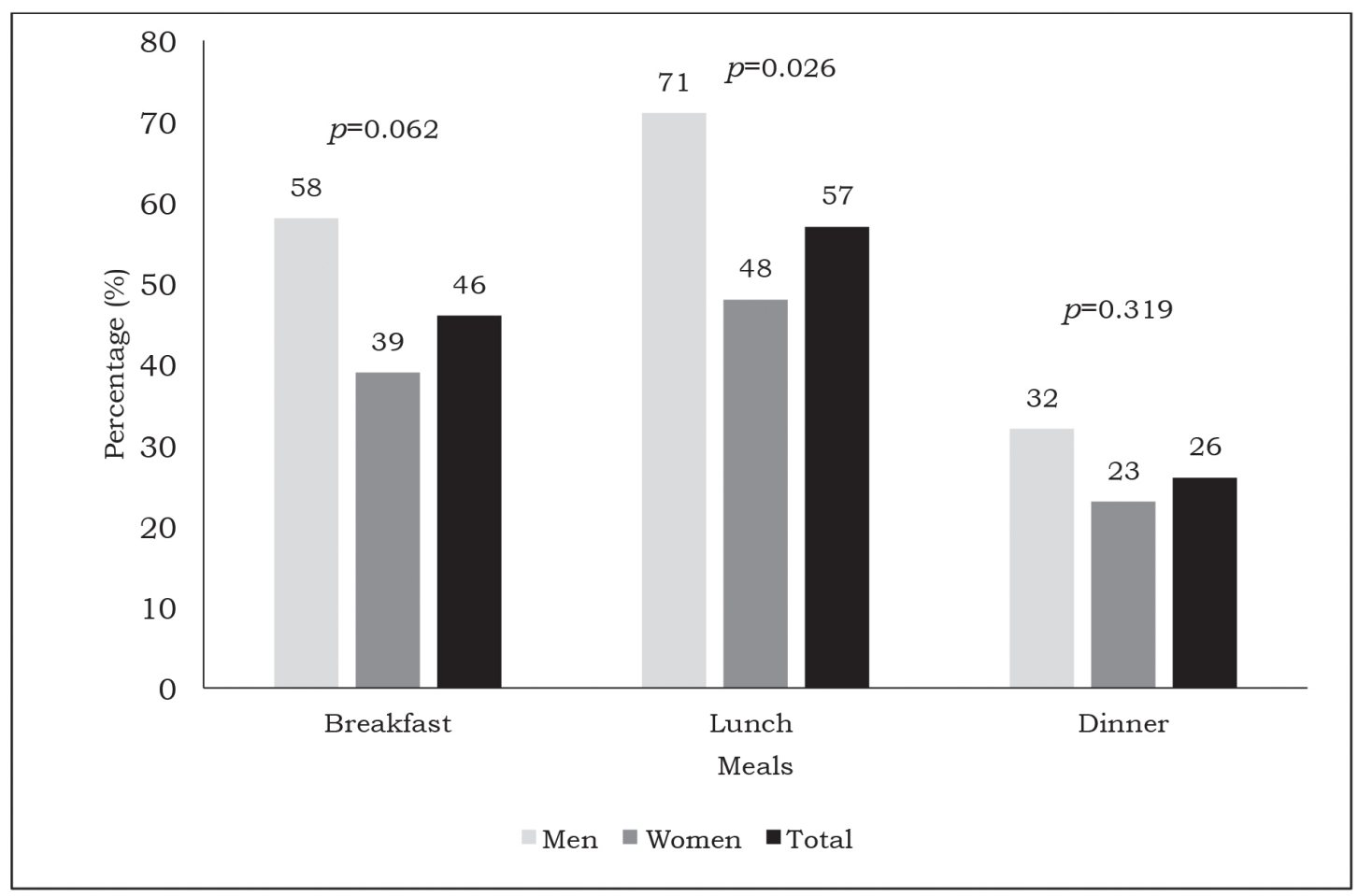

Note. The $p$-values are based on Pearson Chi-square test

Figure 1. Percentage of eating-out among men, women and total respondents according to mealtime

(Zang et al., 2018), though our data found a slightly higher prevalence of eating out. Zang et al. (2018) found that in their study population, slightly more than half $(56 \%)$ of their respondents ate out mostly during lunch (47\%). Our proportion rate was closer to a report from Singapore with an eating-out rate of $77 \%$ (Naidoo et al., 2017). In contrast, in the Singapore study, lunch and dinner were the more common eatingout occasions. The demand increases as the government subsidises hawkers' rental leases, allowing them to sell cooked foods at lower rates (Naidoo et al. 2017). In Metropolis, Brazil, the rate of eating-out was much lower than in Malaysia at 24\% (Gorgulho et al., 2014). Different research designs might have caused differences in research findings. Gorgulho et al. (2014) defined eating-out mainly based on the place of eating-out only, excluding take-away foods. This different approach used to define eatingout resulted in different prevalence.

In this present study, the proportion of eating-out during lunch was significantly higher among men as compared to women. This observation is consistent with a previous study in which men were found to consume outside foods more frequently compared to women (Zang et al., 2018). The norm of men engaging in more social activities, usually taking place in restaurants, may lead to a higher frequency of eatingout (Du et al., 2014). A previous study also found that this trend was more pronounced among male employees with working wives, whereby they tended to eat out and consumed processed foods more often than those whose wives did 
Table 3. Comparison of energy and nutrient intakes between eating-out and eating-in ( $n=91)$

\begin{tabular}{lccc}
\hline Variables & $\begin{array}{c}\text { Out of home } \\
\text { Mean } \pm \text { SE }\end{array}$ & $\begin{array}{c}\text { At home } \\
\text { Mean } \pm \text { SE }\end{array}$ & p-value $^{\dagger}$ \\
\hline Energy (kcal) & $1794 \pm 155$ & $1367 \pm 116$ & 0.269 \\
Protein (g) & $68.9 \pm 2.8$ & $56.0 \pm 5.8$ & 0.074 \\
Carbohydrate (g) & $256.3 \pm 31.9$ & $190.1 \pm 14.7$ & 0.403 \\
Fat (g) & $55.2 \pm 2.9$ & $42.3 \pm 5.2$ & 0.084 \\
Dietary fibre, total (g) & $5.05 \pm 1.43$ & $2.98 \pm 0.42$ & 0.448 \\
Sugar, total (g) & $47.6 \pm 18.5$ & $26.5 \pm 4.0$ & 0.644 \\
Sodium (mg) & $2934 \pm 1311$ & $2165 \pm 1476$ & $0.025^{*}$ \\
\hline
\end{tabular}

${ }^{\dagger} p$-values were based on independent $t$-test, unless otherwise indicated

${ }^{\ddagger}$ Mann-Whitney U test, mediantinterquartile range was reported

${ }^{*} p<0.05$

not work (Park et al., 2017). The higher proportion of those who can cook and prepare meals at home might be a determinant factor of a lower prevalence of eating-out.

From our results, eating-out and eating-in were influenced by the occupation and location of respondents. A lower proportion of eating-out (18\%) than eating-in (44\%) was observed in non-government sectors, as well as in the housewife and not working category (eating-out $21 \%$ vs. eating-in $37 \%$ ). Interestingly, government and semigovernment sectors had the highest proportion of eating-out than eating-in $(61 \%$ vs. $19 \%)$. The exact reasons are unclear; however, a more secure and fixed salary job in the government and semi-government sectors could be a reason since the respondents were less worried about spending their money outside. According to Ali \& Nath (2013), being employed was one of the factors that may influence eating away from home among Indian population in Uttar Pradesh.

Location wise, Kuala Lumpur (urban) reported greater rates of eating-out than eating-in $(57 \%$ vs. $12 \%)$, while Kota Bharu (suburban) reported otherwise. Rapid urbanisation in the Kuala Lumpur city has resulted in a great increase of its population, but also services including transportation, social services, and food outlets such as restaurants, western fast food restaurants, food courts, warung, mamak, hawker stalls, food trucks, etc. These premises are often within a short distance from offices or homes where many are opened around the clock and are often competitive in their pricing. This suggests an association between purchasing power and the accessibility of food stores (d'Amour et al., 2020). These characteristics of food premises in Malaysia may promote eating-out behaviour, and a similar observation was reported by Tian et al. (2016). Tian et al. (2016) reported that populations residing in urban China tended to eat outside more frequently than their rural counterparts and the reason for this difference was thought to be due to lifestyle factors. Ma et al. (2015) reported that the frequency of eating-out among the Chinese population, especially in urban locations, had increased because people were unable to spend much time on food preparation and cooking.

A significantly higher sodium intake was observed among those who consumed outside foods compared to those eating at home. The greater sodium intake is in line with the data obtained by Ruiz et al. (2020), where $80 \%$ of the recommended 
daily sodium intake could be contributed by a single meal outside of the home. This might be due to the misperception of individuals about sodium contents in outside foods. Consumers had poor estimation of sodium in different types of foods. The savoury foods were thought to have high sodium, whilst baked goods were perceived as being lower in sodium. However, research has found that commercial bakeries contained more than $20 \%$ of the recommended daily sodium limit (Moran, Ramirez \& Block, 2017). Interestingly, the present study found comparable energy, protein, carbohydrate, fat, dietary fibre, and sugar intakes between those who consumed foods outside and those who ate at home. This discrepancy might be due to the small sample size. Nevertheless, the trend showed a slightly higher mean intake of these nutrients associated with eating outside.

The possible reasons for high energy and fat intakes when dining outside might be due to the frequent consumption of nasi lemak and roti canai, which are widely available as a local traditional cuisine in Malaysia. Foods away from home are energydense, high in total fat and sugar, and have been found to be associated with poor diet quality (Lachat et al., 2012). A study among the Shanghai population indicated that the daily intakes of total energy, protein, carbohydrate, fat, and iron were increased in people who were dining both at restaurants and company/ school, while the intakes of vitamin B1, zinc, and sodium were increased only in those who ate at restaurants (Zang et al., 2018). A study conducted in 10 European countries found that generally, the levels of vitamin $\mathrm{C}$ and calcium intakes were lower compared with other watersoluble vitamins and minerals among those people who eat outside (Orfanos et al., 2009). Women consuming foods outside had more total fat than protein and carbohydrate intakes, and both men and women who ate outside, especially in southern Europe, had more sugar and starch intakes and lesser total fibre (Orfanos et al., 2009).

The high level of dietary fibre among respondents who practised frequent eating-out might be because they liked to consume vegetables obtained from vegetable soup, tomyam, and mee-hoon soup. The data showed that these foods were cooked and prepared with a variety of vegetables including carrot, mustard green (sawi), cabbage, baby corn, and bean sprouts. In terms of beverages, people dining outside preferred ordering sweet drinks, such as hot teh-o, iced tea, and orange juice, which may promote increased sugar intake in their diet. Dan $\&$ Keke (2016) stated that high amounts of sodium, sugar, and cooking oil, as well as the frying cooking method applied to the preparation of foods away from home, were purposely done to improve the taste, flavour and colour of foods.

Making healthy decisions when eating-out would improve an individual's dietquality. The United States Department of Agriculture (USDA) recommendations include choosing plain water over sugarsweetened beverages, opting for small or medium portions, and choosing dishes with healthy cooking methods, such as steamed, grilled or broiled, versus fried or sautéed. At fast food restaurants, it is recommended for individuals to use available nutrition information to make decisions and passing on "supersizing" (Seguin et al., 2016). Thus, the present study suggests that effective strategies are needed to encourage individuals to prepare foods at home whenever possible and educate them on healthy food choices when eating-out. The government and agencies should also pay more attention to the dietary quality of the government cafeteria. 
More engaging promotional activities on nutrition and health knowledge among workers and the public might help to encourage them in choosing healthier options when eating away from home and to improve their diet quality.

This study has its limitations. Firstly, the cross-sectional design and questionnaire-based methodology did not allow the explanation of factors associated with eating-out habits. Secondly, the findings may not be generalised to all Malaysians due to the non-random sampling method, small sample size, and the incomplete coverage in terms of geographical areas.

\section{CONCLUSION}

In conclusion, the dietary composition of respondents who practised frequent eating-out habits was higher in sodium. Furthermore, being government and semi-government servants and living in urban areas promoted the practice of eating-out. Therefore, the promotion of a healthy diet should be intervened among these groups immediately.

\section{Acknowledgement}

The study was funded by the Long Term Research Grant Scheme (LRGS)-Malaysia Research University Network (MRUN) (203/PPSK/6720021, LRGS/ MRUN/FI/02/2018/01 and LR001-2019) and Lydiatul Shima Ashari was supported by the USM Fellowship scheme.

\section{Authors' contributions}

LSA, designed the study, conducted data collection in the suburban area, data entry, data analysis, and prepared the draft of the manuscript; AAAR, led the data collection in the suburban area, data entry, and prepared the draft of the manuscript; SMR, conceptualised the study, advised on data analysis, and reviewed the manuscript; LYY, reviewed the manuscript; YCK, advised on data analysis and interpretation, and reviewed the manuscript; AHBN, participated in data entry, assisted in data analysis, and assisted in drafting of the manuscript; NHS, led the data collection in the urban area and data entry; RARA, conceptualised the study and reviewed the manuscript; HJJM, conceptualised the study and reviewed the manuscript.

\section{Conflict of interest}

The authors declare that they have no conflict of interest.

\section{References}

Ali J \& Nath T (2013). Factors affecting consumers' eating-out choices in India: implications for the restaurant industry. $J$ Foodserv Bus Res 16(2):197-209.

Ali N \& Abdullah MA (2012). The food consumption and eating behaviour of Malaysian urbanites: issues and concerns. Geografia Malays $J$ Soc Space 8(6):157-165.

Dan Y \& Keke C (2016). Progress in the relationship between eating behavior and overweight, obesity and related indicators. $J$ Health Res 45:1026-1034.

d'Amour CB, Pandey B, Reba M, Ahmad S, Creutzig F \& Seto KC (2020). Urbanization, processed foods, and eating out in India. Glob Food Sec 25:100361.

Deraman MA, Abdul Hafidz MI, Lawenko RM, Ma ZF, Wong MS, Coyle C \& Lee YY (2020). Randomised clinical trial: the effectiveness of Gaviscon Advance vs non-alginate antacid in suppression of acid pocket and post-prandial reflux in obese individuals after late-night supper. Aliment Pharmacol Ther 51(11):10141021.

Du W, Su C, Wang H, Wang Z, Wang Y \& Zhang B (2014). Is density of neighbourhood restaurants associated with BMI in rural Chinese adults? A longitudinal study from the China Health and Nutrition Survey. BMJ Open 4(4):1-8.

EPU (2015). Eleventh Malaysia Plan 2016-2020 Anchoring Growth on People. Prime Minister's Department, Putrajaya.

Fournier T, Tibère L, Laporte C, Mognard E, Ismail MN, Sharif SP \& Poulain JP (2016). Eating patterns and prevalence of obesity. Lessons learned from the Malaysian Food Barometer. Appetite 107:362-371.

Goffe L, Rushton S, White M, Adamson A \& Adams J (2017). Relationship between mean daily energy intake and frequency of consumption of out-of-home meals in the UK National Diet and Nutrition Survey. Int J Behav Nutr Phys Act 14(131):1-11.

Gorgulho BM, Fisberg RM \& Marchioni DML (2014). Away-from-home meals: prevalence and characteristics in a metropolis. Rev Nutr 27(6):703-713. 
IPH (2014). National Health and Morbidity Survey 2014: Malaysian Adult Nutrition Survey (MANS) Vol II: Survey Findings. Institute for Public Health, Kuala Lumpur, Malaysia.

IPH (2011). Album Makanan Malaysia. Tahir A, Suhaila AG, Azli B, Nadrah MH, Yuhanis Auri AK, Nurul Fatihah HG \& Anim Zakiah M (Eds). $1^{\text {st }}$ edn. Institute for Public Health, Kuala Lumpur.

Kim D \& Ahn B-i (2020). Eating out and consumers' health: Evidence on obesity and balanced nutrition intakes. Int $J$ Environ Res Public Health 17(2):1-17.

Lachat C, Nago E, Verstraeten R, Roberfroid D, Van Camp J \& Kolsteren P (2012). Eating out of home and its association with dietary intake: a systematic review of the evidence. Obes Rev 13(4):329-346.

Llanaj E, Ádány R, Lachat C \& D’Haese M (2018). Examining food intake and eating out of home patterns among university students. PLoS One 13(10): 1-14.

Ma G (2015). Food, eating behavior, and culture in Chinese society. J Ethn Foods 2(4):195-199.

Mills SDH, Wolfson JA, Wrieden WL, Brown H, White M \& Adams J (2020). Perceptions of 'home cooking': a qualitative analysis from the United Kingdom and United States. Nutrients 12(1):1-12.

Moran AJ, Ramirez M \& Block JP (2017). Consumer underestimation of sodium in fast food restaurant meals: Results from a cross-sectional observational study. Appetite 113:155-161.

MyFCD (2020). Welcome to Malaysian Food Composition Database (MyFCD). From https: / / myfcd.moh.gov.my/. [Retrieved October 1 2020].

Naidoo N, van Dam RM, Ng S, Tan CS, Chen S, Lim JY, Chan MF, Chew L \& Rebello SA (2017). Determinants of eating at local and western fast-food venues in an urban Asian population: a mixed methods approach. Int $J$ Behav Nutr Phys Act 14(69):1-12.

NCCFN (2019). Malaysian Dietary Guidelines. National Coordinating Committee on Food and Nutrition, Ministry of Health Malaysia, Putrajaya.
Orfanos P, Naska A, Trichopoulou A, Grioni S, Boer J, Van Bakel M, Ericson U, Rohrmann S, Boeing H \& Rodriguez L (2009). Eating out of home: energy, macro-and micronutrient intakes in 10 European countries. The European Prospective Investigation into Cancer and Nutrition. Eur $J$ Clin Nutr 63(4):S239-S262.

Park S, Sung E, Choi Y, Ryu S, Chang Y \& Gittelsohn J (2017). Sociocultural factors influencing eating practices among office workers in urban South Korea. J Nutr Educ Behav 49(6):466-474.

Poulain JP, Laporte C, Tibère L, Mognard E, Ragavan NA, Zadeh AA \& Noor IM (2020). Malaysian Food Barometer (MFB): a study of the impact of compressed modernisation on food habits. Malays J Nutr 26(1):1-17.

Ruiz AMP, Lima MG, Medina LDPB, Pinto RL, Barros MBDA \& Filho ADAB (2020). Can meals outside homes impact sodium intake?. Curr Dev Nutr 4(6): 1-8.

Seguin RA, Aggarwal A, Vermeylen F \& Drewnowski A (2016). Consumption frequency of foods away from home linked with higher body mass index and lower fruit and vegetable Intake among adults: a cross-sectional study. $J$ Environ Public Health 2016:1-12.

Suzana S, Nik Shanita S, Zahara AM \& Hasnah H (2015). Atlas of Food Exchange \& Portion Sizes ( $3^{\text {rd }}$ edn). MDC Publishers Sdn. Bhd, Kuala Lumpur.

Tee ES, Ismail MN, Nasir MA \& Khatijah I (1997). Nutrient Composition of Malaysian Foods. $\left(4^{\text {th }}\right.$ edn). Malaysian Food Composition Database Programme. Institute for Medical Research, Kuala Lumpur.

Tian X, Zhong L, von Cramon-Taubadel S, Tu $H$ \& Wang $H$ (2016). Restaurants in the neighborhood, eating away from home and BMI in China. PLoS One 11(12):1-16.

Zang J, Luo B, Wang Y, Zhu Z, Wang Z, He X, Wang W, Guo Y, Chen X \& Wang C (2018). Eating out-of-home in adult residents in Shanghai and the nutritional differences among dining places. Nutrients 10(7):1-13. 